\title{
Electrocardiogram and vectorcardiogram in Turner phenotype with normal chromosomes and pulmonary stenosis
}

\author{
Knut Rasmussen ${ }^{1}$ and Svein J. Sørland \\ From Medical Department B and Cardiac Section, Pediatric Department, University Hospital, \\ Rikshospitalet, Oslo, Norway
}

Electrocardiograms and vectorcardiograms from 7 boys with the 'Ullrich-Turner phenotype', pulmonary stenosis, and normal chromosomes were systematically compared with recordings from 37 unselected patients with uncomplicated pulmonary stenosis. The 7 patients had a highly characteristic QRS pattern which differed greatly from that of the control group. The frontal plane $Q R S$ loop was almost completely localized to the upper right quadrant with a mean frontal $Q R S$ axis between 180 and 240 degrees. Initial leftward and inferior forces were minimal. Quantitative criteria were found which gave complete separation of the two groups.

The relation between the electrocardiogram and right ventricular systolic pressure was clearly atypical in the Ullich-Turner phenotype patients. At each pressure level the posterior and rightward forces exceeded by far the corresponding forces of the control group.

The pattern may be caused either by abnormalities of the specialized conduction system or by an atypical kind of ventricular hypertrophy in these subjects.

It has been known for some time that subjects with features resembling those described by Turner (1938) in adult women, but without sex anomaly and with normal sex chromosomes, have an increased incidence of various congenital cardiac lesions. This clinical syndrome is seen in both sexes and the autosomal complement is generally normal. In males the condition has been usually described as 'male Turner's syndrome' (see e.g. Levy et al., I970), but at times the eponym of 'Ullrich's syndrome' has been used (Siggers and Polani, 1972). Most of these male subjects with 'Ullrich-Turner's phenotype' have short stature, skeletal anomalies, cryptorchidism, mild intellectual retardation, hydronephrosis, a peculiar facies; and webbing of the neck is an essential trait. Recently, a subgroup of the 'Ullrich-Turner phenotype' characterized by pulmonary valve stenosis, and a normal chromosome complement, has been more clearly defined (Noonan and Ehmke, 1963), but webbing of the neck does not seem to be an obligatory clinical association.

Received 5 April 1973.

${ }_{1}^{1}$ Research fellow, The Norwegian Research Council for Science and The Humanities.
In 1968, Noonan reported that the electrocardiogram in these patients might differ from that usually found in 'pure' pulmonary stenosis, especially with regard to an extreme right axis deviation and an unusually small $\mathbf{R}$ in lead VI. Similar observations have been made by others (Celermajer, Bowdler, and Cohen, 1968; Dupuis et al., 197I). The aim of this report is to document these and other characteristics of the electrocardiogram and vectorcardiogram in further detail.

\section{Subjects and methods}

During the past 2 years 7 patients have been seen with the Ullich-Turner's phenotype and pulmonary stenosis (Table I). We shall use this double eponym here but wish to stress that not all our patients had neck webbing. All were boys and all had a normal chromosome complement. Six of the patients had valvular pulmonary stenosis, while one (Case 2) had a discrete infundibular stenosis. Three patients had additional small atrial septal defects. Two patients had been unsuccessfully operated on three years previously.

In order to clarify the characteristics of the electrocardiographic pattern in this syndrome, the group was 
TABLE I Clinical and haemodynamic data in patients with $X Y$ Ullrich-Turner's phenotype, ranged according to right ventricular pressure

\begin{tabular}{|c|c|c|c|c|c|c|c|}
\hline \multirow{3}{*}{$\begin{array}{l}\text { Age (yr) } \\
\text { Right ventricular peak systolic pressure } \\
(\mathrm{mmHg})\end{array}$} & \multicolumn{6}{|c|}{ Case No. } & 7 \\
\hline & 6 & 9 & 5 & $2 \cdot 5$ & 8 & 8 & 9 \\
\hline & $4 I$ & 74 & 80 & 132 & I40 & 140 & I54 \\
\hline Pulmonary to systemic flow ratio & I, 3 & I & $\mathbf{I}$ & I & I & I, 3 & I, 5 \\
\hline Growth retardation & ++ & + & + & + & - & ++ & + \\
\hline Mental retardation & + & + & $(+)$ & + & - & + & - \\
\hline Hypertelorism & + & ++ & $(+)$ & + & + & $(+)$ & + \\
\hline Ptosis & $(+)$ & + & - & - & $(+)$ & - & + \\
\hline Chest deformity & ++ & + & + & + & + & $(+)$ & + \\
\hline Undescended testis & - & + & + & + & + & + & $+t$ \\
\hline Hydronephrosis & - & - & + & + & + & - & - \\
\hline Webbed neck & - & + & + & + & $(+)$ & - & + \\
\hline
\end{tabular}

compared with 37 consecutive nonselected patients with isolated unoperated pulmonary stenosis and otherwise normal somatic features. The mean age of the control group was 16 years compared with 7 years in the UllrichTurner phenotype group. Neither this difference nor the presence of small atrial septal defects in the 3 subjects was thought to invalidate the comparison between the groups. Mean right ventricular systolic pressure in the Turner phenotype group was rog $\mathrm{mmHg}$, and in the control group $85 \mathrm{mmHg}$.

A I2-lead electrocardiogram was recorded with an Elema Schönander Mingograf. Vectorcardiogram was recorded with the axial lead system (McFee and Parungao, 196I) using a Sanborn I85 B amplifier and a 569B Visoscope. Ordinary axis orientation was used. Planar vector loops were photographed with a beam interruption interval of $2.5 \mathrm{msec}$. Scalar $\mathrm{X}, \mathrm{Y}$, and $\mathrm{Z}$ leads were recorded with a Mingograf, using both 50 and 250 $\mathrm{mm} / \mathrm{sec}$ paper speed. Spatial vector magnitudes and angular data were derived for each Io msec $Q R S$ vector from the planar recordings, while maxima and minima were derived from the scalar recordings. All these data were systematically compared in the two groups of subjects.

TABLE 2 Comparison of selected scalar vectorcardiographic and electrocardiographic data in two groups

\begin{tabular}{|c|c|c|c|c|c|c|c|}
\hline \multirow[t]{2}{*}{ Parameter } & \multicolumn{2}{|c|}{ Turner phenotype $(N=7)$} & \multicolumn{2}{|c|}{ Control $(N=37)$} & \multirow[t]{2}{*}{$t$} & \multirow[t]{2}{*}{$P$} & \multirow{2}{*}{$\begin{array}{l}\text { No. of control subjects } \\
\text { overlapping Turner } \\
\text { phenotype subjects }\end{array}$} \\
\hline & Mean $(m V)$ & Range & Mean $(m V)$ & Range & & & \\
\hline $\begin{array}{l}\text { Vectorcardiogra } \\
\mathbf{X}_{30} \\
\mathbf{X}_{40} \\
\mathbf{X}_{\mathbf{X}}-\max _{\mathbf{F}} \\
\mathbf{X}-\max \\
\mathbf{X}-\min _{2} \\
\mathbf{Y}_{30} \\
\mathbf{Y}_{40} \\
\text { X-max } \\
\text { Y-max } \\
\text { Y-min } \\
\text { Y-max-Y-min } \\
\text { Z-max }\end{array}$ & $\begin{array}{l}-0.59 \\
-1.84 \\
-2.12 \\
+0.16 \\
-2.36 \\
-0.13 \\
-0.60 \\
-1.44 \\
+0.19 \\
-1.67 \\
-1.48 \\
+1.92\end{array}$ & $\begin{array}{l}-1.25-+0.20 \\
-3.05--0.10 \\
-3.80-1.50 \\
+0.00-+0.35 \\
-3.80-1.45 \\
-0.52-+0.55 \\
-0.80-0.40 \\
-3.60-0.25 \\
+0.05-+0.55 \\
-3.60-1.00 \\
-3.50-0.70 \\
+1.05-+3.90\end{array}$ & $\begin{array}{l}+0.70 \\
+0.44 \\
+0.22 \\
+1 \cdot 28 \\
-1 \cdot 11 \\
+0.64 \\
+0.92 \\
+1 \cdot 22 \\
+1 \cdot 47 \\
-0.34 \\
+1 \cdot 13 \\
+0.69\end{array}$ & $\begin{array}{l}-1 \cdot 25-+1 \cdot 40 \\
-2 \cdot 30-+1.90 \\
-3.05-+2 \cdot 20 \\
+0.40-+2.20 \\
-3.70-0.00 \\
-0.30-+2 \cdot 10 \\
-1.00-+2.50 \\
-1.20-+3.10 \\
+0.50-+3.10 \\
-1.30-0.00 \\
-0.50-+2.90 \\
0.00-+1.77\end{array}$ & $\begin{array}{l}5 \cdot 5 \\
5 \cdot 4 \\
4 \cdot 1 \\
7 \cdot 3 \\
4 \cdot 3 \\
4 \cdot 2 \\
5 \cdot 3 \\
7 \cdot 6 \\
5 \cdot 4 \\
7 \cdot 2 \\
7 \cdot 7 \\
5 \cdot 2\end{array}$ & $\begin{array}{l}<0.001 \\
<0.001 \\
<0.001 \\
<0.001 \\
<0.001 \\
<0.001 \\
<0.001 \\
<0.001 \\
<0.001 \\
<0.001 \\
<0.001 \\
<0.001\end{array}$ & $\begin{array}{l}6 \\
\text { II } \\
6 \\
0 \\
8 \\
\text { I7 } \\
2 \text { (No. } 26 \text { and 28) } \\
\text { I (No. 26) } \\
\text { I (No. 4) } \\
\text { I (No. 26) } \\
0 \\
\text { I0 }\end{array}$ \\
\hline $\begin{array}{l}E C G: \\
\text { R I } \\
\text { R V6 } \\
\text { S V6 } \\
\text { R aVF } \\
S \text { aVF } \\
\text { R/S aVF } \\
R \text { aVR } \\
S \text { or Q aVR }\end{array}$ & $\begin{array}{l}0.14 \\
0.11 \\
1.52 \\
0.18 \\
1.09 \\
0.19 \\
1.36 \\
0.10\end{array}$ & $\begin{array}{l}0.00-0.25 \\
0.00-0.35 \\
0.75-2.20 \\
0.05-0.40 \\
0.60-2.20 \\
0.05-0.44 \\
0.85-2.40 \\
0.00-0.15\end{array}$ & $\begin{array}{l}0.56 \\
1 \cdot 17 \\
0.49 \\
0.96 \\
0.29 \\
8.3 \\
0.53 \\
0.66\end{array}$ & $\begin{array}{l}0.10-1.60 \\
0.10-2.10 \\
0.00-1.50 \\
0.20-2.00 \\
0.00-1.00 \\
0.60-30.00 \\
0.05-1.40 \\
0.20-1.15\end{array}$ & $\begin{array}{l}4 \cdot 0 \\
6 \cdot 1 \\
6 \cdot 0 \\
4 \cdot 5 \\
6 \cdot 2 \\
2 \cdot 1 \\
5 \cdot 8 \\
6 \cdot 0\end{array}$ & $\begin{array}{l}<0.001 \\
<0.001 \\
<0.001 \\
<0.001 \\
<0.001 \\
<0.05 \\
<0.001 \\
<0.001\end{array}$ & $\begin{array}{l}5 \\
1 \text { (No. 17) } \\
9 \\
3 \text { (No. 5, 6, and 28) } \\
5 \\
0 \\
7 \\
0\end{array}$ \\
\hline
\end{tabular}

Abbreviations used in the Table: $X_{20}$, etc. $=X$ at 20 msec after $Q R S$ onset, etc. $X$-max $F=X$ at maximal $Q R S$ projection in frontal plane. $R$ aVR $=$ maximal $R$ or $R^{\prime}$. 
Right heart catheterization had been performed in all the cases, and in most within a few days of the electrocardiogram and vectorcardiogram. Right ventricular angiograms had been made in all with a right ventricular systolic pressure above $50 \mathrm{mmHg}$

Standard t-test and linear regression analysis were used in the statistical evaluations.

\section{Results}

Electrocardiograms from the 7 patients with Ullrich-Turner's phenotype are shown in Fig. I and 2. A uniform and characteristic pattern was found, with extreme right axis deviation to more than 180 degrees, small or absent $R$ waves in leads $I, V 6$, and $a V F$, and large $R$ waves in aVR. In two patients the $R$ waves in VI were surprisingly small. $P$ waves and PR segments were normal and the $T$ waves were uniformly discordant to the QRS.

Frontal and horizontal plane vector loops are presented in Fig. 3 and 4. In the frontal plane, almost the complete QRS loop was localized to the upper right quadrant. The rotation in this plane was clockwise in all cases except Case 2, in which a counterclockwise rotation and a more superiorly oriented loop was found. The T loops were completely discordant to the QRS loops. In the hori-

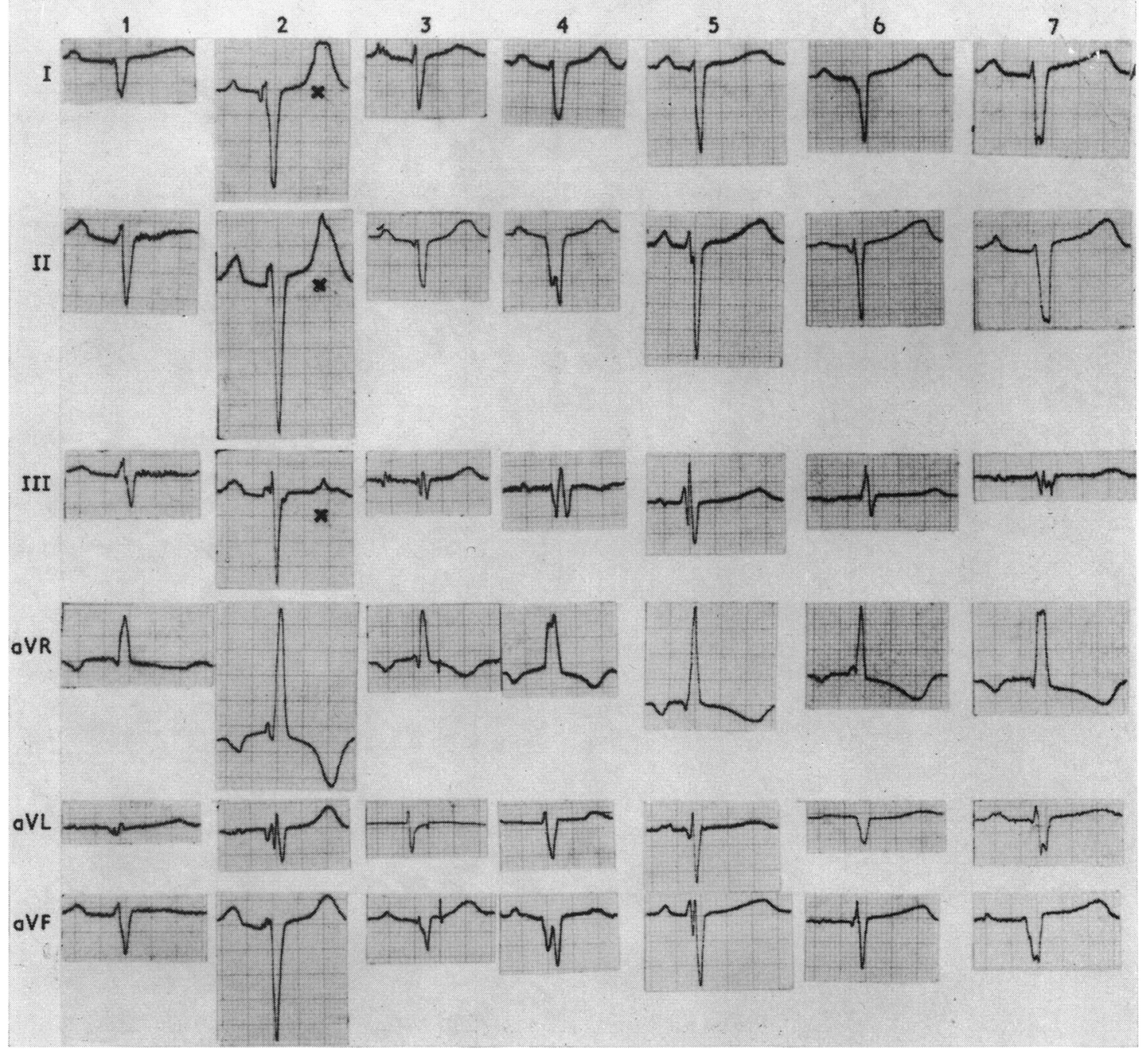

FIG. I Extremity electrocardiogram leads for the 7 patients with the Turner phenotype. Case numbering corresponding to Table I. Paper speed: $50 \mathrm{~mm} / \mathrm{sec}$. Calibration: $1 \mathrm{mV}=10 \mathrm{~mm}$. The complexes marked with a cross (Case 2) have an ectopic atrial $P$ wave superposed on the $T$ wave. 
zontal plane the picture was more varied. The 4 patients with the highest right ventricular pressures had loop configurations about as expected, but the other 3 had posteriorly dislocated loops with unexpected counterclockwise rotation in 2 of them.
Some of the significant results from the statistical comparison of the two groups are presented in Table 2. A large number of measurements differed significantly in the two groups and four of the corresponding criteria separated them completely

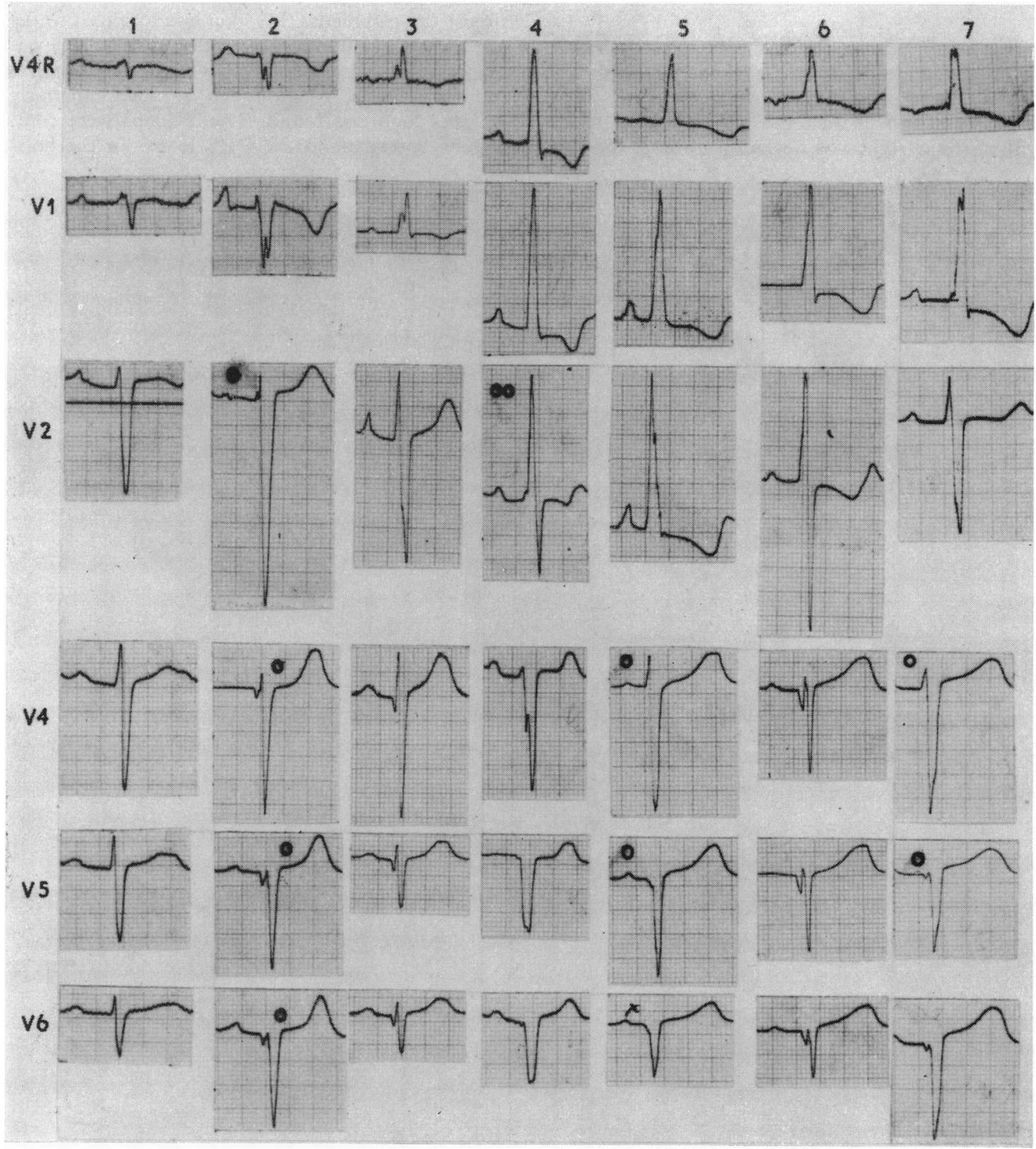

FIG. 2 Praecordial electrocardiograph leads for the 7 patients with the Turner phenotype. Patient numbering corresponding to Table I. Paper speed and calibration as in Fig. I except for tracings marked o where $I \mathrm{mV}=5 \mathrm{~mm}$ and tracing marked oo where $I \mathrm{mV}=7 \mathrm{~mm}$. 
from each other. These criteria for the Turner phenotype were: (I) maximal positive deflection in lead $\mathrm{X}$ less than $0.4 \mathrm{mV}$; (2) maximal negative minus maximal positive deflection in lead $\mathrm{Y}$ exceeding $0.5 \mathrm{mV}$; (3) $\mathrm{R} / \mathrm{S}$ ratio in lead aVF less than 0.6 ; and (4) maximal negative deflection in lead aVR ( $S$ or $Q$ ) less than $0.2 \mathrm{mV}$. Several other criteria gave almost complete discrimination.

Frontal plane angular data are shown in Fig. 5, also demonstrating the large differences between the groups. A criterion based on a $30 \mathrm{msec}$ frontal angle between 100 and 330 degrees gives complete separation of the groups.

Both scalar and angular data show that the initial QRS vectors were not significantly altered in the Turner phenotype group, but from 15 to $20 \mathrm{msec}$ after the onset of ventricular depolarization the process takes entirely different directions.

For all types of electrocardiograph measurements a large scatter of values was found, reflecting the dominant influence of right ventricular pressure on the electrocardiogram in pulmonary stenosis. There-

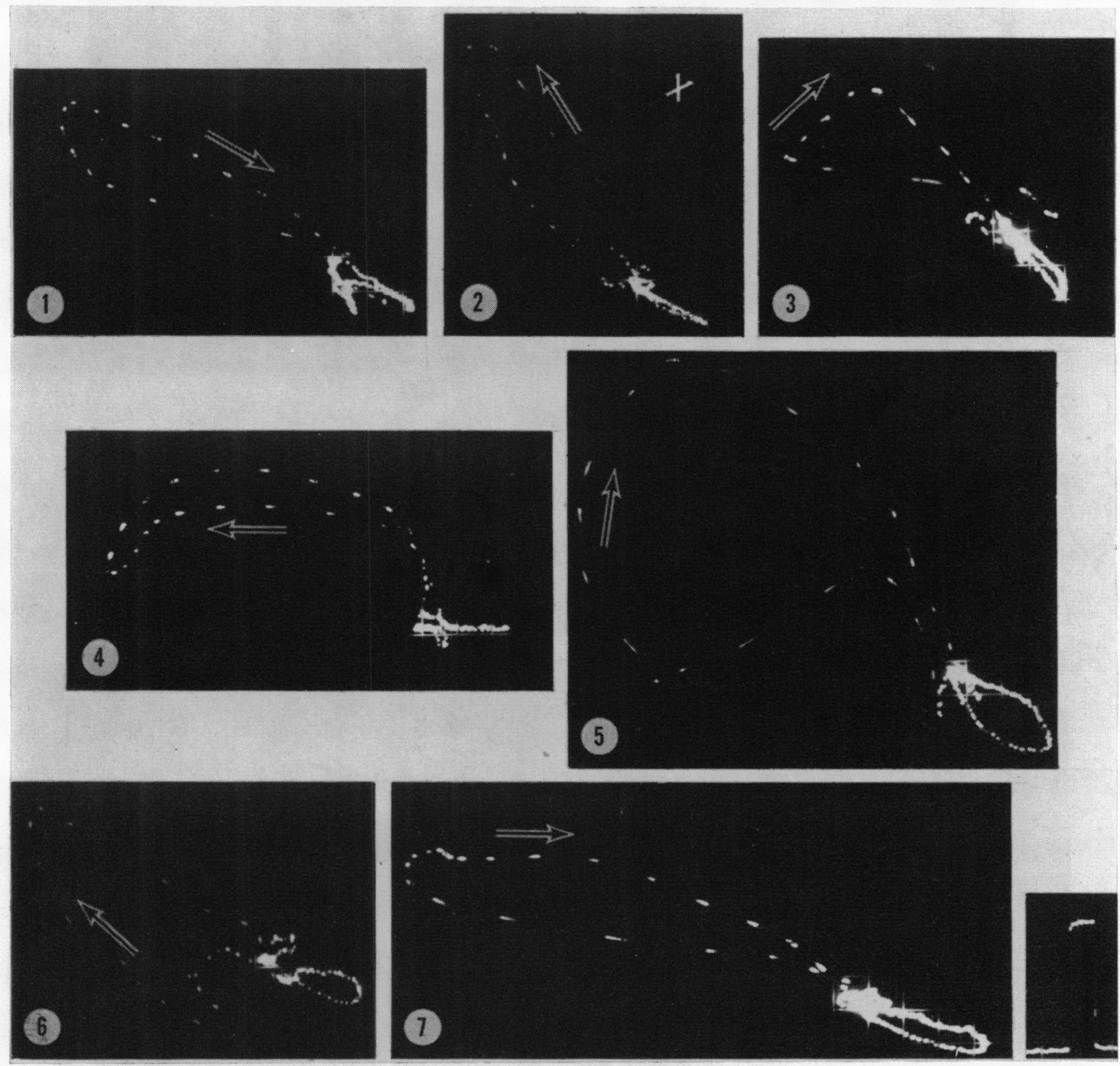

FIG. 3 Frontal plane vectorcardiograph loops in the 7 patients with the Turner phenotype. Case numbering as in Table 1 . Beam interruption interval, 2.5 msec. Calibration signal, I $m V$. Tracings marked with a cross have been calibrated to one-half of this. Arrows indicate the direction of loop rotation. 
FIG. 4 Horizontal plane vectorcardiograph loops for the 7 patients. Recording conditions as in Fig. 3. Calibration as in Fig. 3. Arrows indicate the direction of loop rotation. 


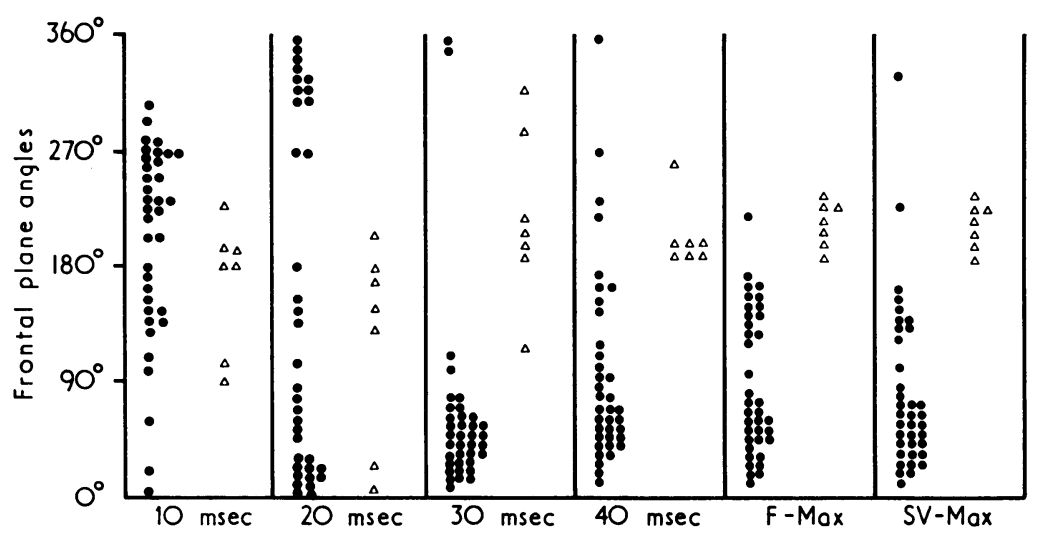

FIG. 5 Frontal plane angles for the initial 10 msec vectors, for the maximal vector in the frontal plane $\left(F_{\max }\right)$, and for the frontal projection of the maximal spatial $Q R S$ vector $\left(S V_{\max }\right)$ in control (filled circles) and Turner phenotype (triangles) group. One patient is missing in the control group at $10 \mathrm{msec}$ and two are missing at $20 \mathrm{msec}$ because the instantaneous vectors did not have any frontal projection.

fore, adjustment for this factor was made through a comparison of the correlations between scalar vectorcardiographic data and right ventricular systolic pressure in the two groups. Maximal superior, inferior, and leftward forces, which best separated the two groups (Table 2), were not significantly correlated with pressure. The criteria for discrimination based on these measurements may therefore be used without consideration of the degree of pulmonary stenosis. Posterior (Fig. 6) and rightward (Fig. 7)

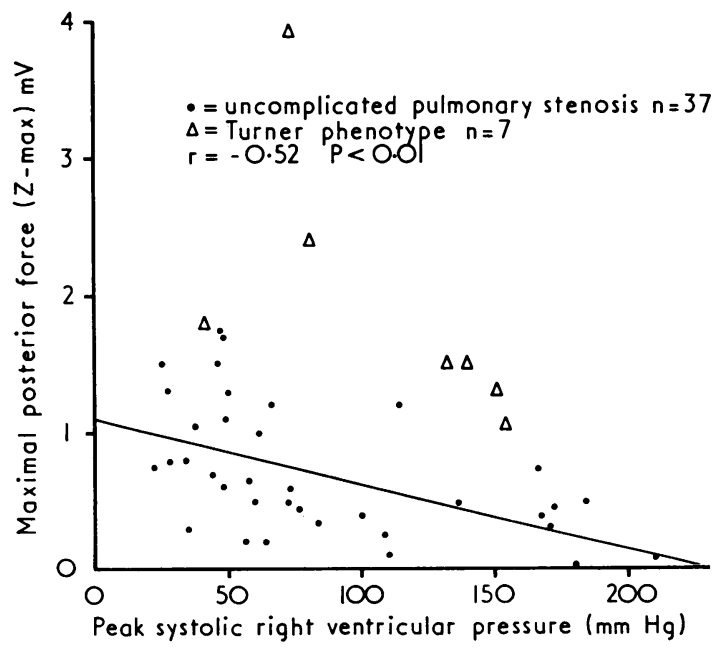

FIG. 6 Maximal posterior forces in scalar vectorcardiogram plotted against peak right ventricular systolic pressure. The regression line and its formula, in this and Fig. 7, have been calculated from the control data only. forces were significantly related to pressure in the control group, and in both these directions the 7 patients showed considerably larger forces than expected. A regression line for the values in these patients about parallel with that of the control patients may be suggested. Anterior forces were also highly related to pressure, but the difference between the two groups in the pressure electrocardiogram relation was not so evident in this direction.

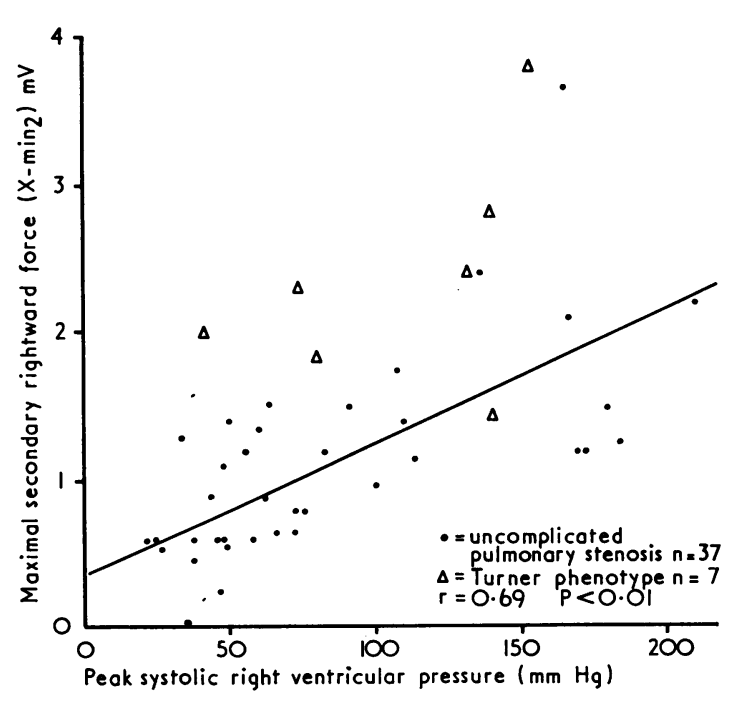

FIG. 7 Maximal secondary rightward (after $20 \mathrm{msec}$ of $Q R S$ ) vectorcardiograph forces plotted against peak systolic right ventricular pressure. 


\section{Discussion}

The data presented establish that subjects with Ullrich-Turner's phenotype and pulmonary stenosis as a group have an electrocardiographic pattern distinctly different from that found in uncomplicated pulmonary stenosis. From this conclusion two important practical consequences emerge. First, this pattern may be of help in the identification of this syndrome and may thus contribute to the recognition of other anomalies linked with it. Clearly, the establishing of the exact specificity and sensitivity of the presented pattern must wait until a larger sample has been studied. When this has been done all the criteria proposed will probably become less sensitive and specific. This applies especially to the sensitivity, since the number of patients with the Ullrich-Turner phenotype was so small. Already, similar patients have been described without any atypical features in the electrocardiogram (Celemajer et al., 1968; Dupuis et al., 197I). One obstacle in the clarification of this problem will be the many syndrome definitions used in this field (Siggers and Polani, 1972).

Because the control group was fairly large, the high specificity found is more reliable. Previous reports indicate that patients with pulmonary stenosis occasionally may have a right axis deviation to more than I80 degrees (Scherlis, Koenker, and Lee, 1963; Tandon, Nadas, and Gross, 1965). Burch and DePasquale (I96I) have described patients with pulmonary stenosis and atrial septal defects with a superior rightward axis. However, since these series may have included patients with the special phenotype under discussion, we elected to study a new series of control patients. Our conclusion is that the finding of the described electrocardiographic pattern in a subject with probable pulmonary stenosis warrants a close search for the other features of the Turner phenotype syndrome. During the same period as the 7 patients were observed, about I00 children with pulmonary stenosis were seen in our hospital, giving a proportion of about 7 per cent. This is in good agreement with the figures of Celermajer et al. (1968).

The high specificity will, however, also be reduced when all other kinds of heart disease are considered. Several types of congenital heart disease, including tetralogy of Fallot, transposition of the great arteries, and AV septal defects, may have a frontal QRS axis between 180 and 270 degrees (Martins de Oliveira et al., 1959; Ayala y de Landero et al., 1959). Transpositions do also frequently have small initial inferior and leftward forces, giving a pattern very similar to that described here. However, these patients can usually be differentiated clinically from those with Ullrich-Turner phenotype and pulmonary stenosis. AV septal defects can be separated from the presently described subjects by means of the more superiorly oriented QRS axis (around 270 degrees), the larger initial leftward forces, and the constant counterclockwise rotation of the frontal QRS loop.

The second practical implication is that the commonly applied and usually highly reliable electrocardiographic and vectorcardiographic criteria for evaluating the degree of pulmonary stenosis cannot be used in this group (Strang et al., 1963; Scherlis et al., 1963; Witham, Rainey, and Edmonds, 1968; Gamboa, Hugenholtz, and Nadas, I966). If criteria based on loss of leftward and increase in rightward forces ( $S$ in lead I and V6, R in lead I and V6, R in lead aVR and maximal rightward spatial vector) are used, right ventricular systolic pressure can be seriously overestimated. Correspondingly, the use of anterior-posterior force relation ( $R$ or $R / S \mathrm{VI}-2$, maximal anterior or posterior vectors) may lead to serious underestimation of pressure. The latter situation is perhaps the most common (Noonan, I968).

During the past years several successful efforts have been made to correlate electrocardiogram and vectorcardiogram with haemodynamic data in pulmonary stenosis (Witham et al., 1968; Gamboa et al., I966). Patients with the presently described atypical pattern obviously represent one source of persisting variation in such studies. Improved correlations may be expected when these patients are treated as a separate entity.

The aetiology of the disturbance of ventricular depolarization is unknown and will remain so until anatomical and electrophysiological data from these patients have been presented. Recently, Ehlers et al. (1972) have reported eccentric ventricular hypertrophy with an abnormal left ventricle in patients with the Ullrich-Turner phenotype. Three of their 5 subjects with pulmonary stenosis had this hypertrophy and in all of them a superior QRS axis was found. In our case with a discrete infundibular stenosis the left ventricle was divided in two by a muscular ridge. In the other 6 no definite left ventricular abnormalities were found. It is also difficult to understand how left-sided eccentric hypertrophy alone may explain the genesis of this profound disturbance of depolarization. As also suggested by Ehlers et al. (1972), another possible cause is a specific disturbance of function or anatomy of the specialized conduction system, by analogy with the conduction system in AV defects. This may cause early depolarization of inferior-leftward parts of the heart with subsequent depolarization fronts moving up and rightwards. 


\section{References}

Ayala y de Landero, C., Luzardo-Ramires, G., Sanchez, J., and Sodi-Pallares, D (1959). The mean manifest electrical axes of ventricular activation and repolarization processes (ÂQRS and ÂT) in congenital heart disease: frontal and horizontal planes. American Heart fournal, 58, 889.

Burch, G. E., and DePasquale, N. P. (196I). The electrocardiogram, vectorcardiogram and ventricular gradient in combined pulmonary stenosis and interatrial communication. American fournal of Cardiology, 7, 646.

Celermajer, J. M., Bowdler, J. D., and Cohen, D. H. (1968). Pulmonary stenosis in patients with the Turner phenotype in the male. American fournal of Diseases of Children, 116, 351.

Dupuis, C., Deminatti, M., Maillard, E., Nuyts, J. P., Cousin, J., Frison, B., and Walbaum, R. (I97I). Les cardiopathies du syndrome d'Ullrich-Turner. Archives Francaises de Pédiatrie, 28, 395.

Ehlers, K. H., Engle, M. A., Levin, A. R., and Deely, W. J. (1972). Eccentric ventricular hypertrophy in familial and sporadic instances of $46 \mathrm{XX}, \mathrm{XY}$ Turner phenotype. Circulation, 45, 639.

Gamboa, R., Hugenholtz, P. G., and Nadas, A. S. (1966). Corrected (Frank), uncorrected (Cube), and standard electrocardiographic lead systems in recording augmented right ventricular forces in right ventricular hypertension. British Heart fournal, 28, 62.

Levy, E. P., Pashayan, H., Fraser, F. C., and Pinsky, L. (1970). $\mathrm{XX}$ and XY Turner phenotypes in a family. American Fournal of Diseases of Children, 120, 36.

McFee, R., and Parungao, A. (I96r). An orthogonal lead system for clinical electrocardiography. American Heart fournal, 62, 93.

Martins de Oliveira, J., Carballo, R., Imperial, E. S., Tranchesi, J., and Zimmerman, H. A. (1959). The mean ven- tricular axis in congenital heart disease: a study considering the natural incidence of the malformations. American Heart fournal, 57, 820.

Noonan, J. A. (1968). Hypertelorism with Turner phenotype. A new syndrome with associated congenital heart disease. American fournal of Diseases of Children, 116, 373.

Noonan, J. A., and Ehmke, D. A. (1963). Associated noncardiac malformations in children with congenital heart disease. Fournal of Pediatrics, 63, 468.

Scherlis, L., Koenker, R. J., and Lee, Y. C. (1963). Pulmonary stenosis. Electrocardiographic, vectorcardiographic, and catheterization data. Circulation, 28, 288.

Siggers, D. C., and Polani, P. E. (1972). Congenital heart disease in male and female subjects with somatic features of Turner's syndrome and normal sex chromosomes (Ullrich's and related syndromes). British Heart fournal, 34, 4I.

Strang, R. H., Hugenholtz, P. G., Liebman, J., and Nadas, A. S. (1963). The vectorcardiogram in pulmonary stenosis. Correlation with the hemodynamic state in patients with and without ventricular septal defect. American fournal of Cardiology, 12, 758.

Tandon, R., Nadas, A. S., and Gross, R. E. (1965). Results of open-heart surgery in patients with pulmonic stenosis and intact ventricular septum. A report of 108 cases. Circulation, 31, 190.

Turner, H. H. (1938). A syndrome of infantilism, congenital webbed neck, and cubitus valgus. Endocrinology, 23, 566.

Witham, A. C., Rainey, R. L., and Edmonds, J. H. (I968). Prediction of right ventricular pressure in pulmonic stenosis from sponge vectorcardiogram and electrocardiogram. American Heart fournal, 75, 187.

Requests for reprints to Dr. Knut Rasmussen, Medical Department B, University Hospital, Rikshospitalet, Oslo, Norway. 